\title{
Validity and Reliability of the Amharic Version of EORTC-QLQ-CR29 Among Colorectal Cancer Patients in Ethiopia
}

Lidya Genene Abebe (D)'

Abigiya Wondimagegnehu ${ }^{1,2}$

Aynalem Abraha

Woldemariam ${ }^{3, \dagger}$

Bizu Gelaye ${ }^{4,5}$

Eva Johanna Kantelhardt ${ }^{2,6}$

Adamu Addissie ${ }^{1,2}$

'Department of Preventive Medicine, School of Public Health, College of Health Sciences, Addis Ababa University, Addis Ababa, Ethiopia; ${ }^{2}$ Institute of Medical Epidemiology, Biometrics and Informatics, Martin-Luther-University, Halle-Wittenberg, Halle, Germany;

${ }^{3}$ Department of Oncology and Radiotherapy, School of Medicine, College of Health Sciences, Addis Ababa University, Addis Ababa, Ethiopia; ${ }^{4}$ Department of Epidemiology, Harvard. T. H. Chan School of Public Health, Boston, MA, USA; ${ }^{5}$ The Chester M. Pierce, M.D. Division of Global Psychiatry, Massachusetts General Hospital, Boston, MA, USA; ${ }^{6}$ Department of Gynaecology, Martin-LutherUniversity, Halle-Wittenberg, Halle, Germany

${ }^{\dagger}$ Aynalem Abraha Woldemariam passed away on April 9, 2021
Correspondence: Lidya Genene Abebe Tel +25I 912665940

Email lidyagenene@gmail.com
Background: The European Organization for Research and Treatment of Cancer - Quality of Life Questionnaire (EORTC-QLQ) developed to assess quality of life among colorectal cancer patients has not been translated into a local language or validated in the Ethiopian context. Therefore, this study aimed to examine the psychometric properties of the EORTCQLQ-CR29 tool in Ethiopia among colorectal cancer patients.

Methods: A cross-sectional study was conducted in a major referral hospital in Addis Ababa, Ethiopia, from March to May, 2020. A total of 158 colorectal cancer patients were included. The validity of the tool was assessed using Multitrait Scale Analysis, MannWhitney test and Pearson correlation coefficient. The internal consistency was examined using Cronbach's alpha.

Results: Among the participants, $52.2 \%$ were men, with a median age of 46 years (IQR = 17.7 years). The item-total correlation alpha values ranged from 0.47 to 0.91 . Multitrait Scale Analysis demonstrated convergent and divergent validity of the tool, except for the Blood and Mucus in Stool scale. All item correlations within their scales were greater than 0.4, except for the Blood and Mucus in Stool scale. The values of correlation coefficients between all items and their own domain were higher than other domains, except for the Blood and Mucus in Stool scale. The correlation between the core questionnaire and the colorectal tool ranged from -0.45 to 0.58 . The tool showed a significant difference between stoma and non-stoma patients and between patients who had good physical function and those who did not.

Conclusion: The Amharic version of the EORTC-QLQ-CR29 tool can be used to assess the health-related quality of life in Ethiopian colorectal cancer patients.

Keywords: validity, EORTC-QLQ, colorectal cancer, Ethiopia

\section{Introduction}

Colorectal cancer is the third leading cause of cancer cases worldwide. In 2018 , there were more than 1.8 million new cases and 881,000 deaths from colorectal cancer. ${ }^{1}$ The incidence of colorectal cancer is higher in high-income countries, but the mortality is higher in low- and middle-income countries. In Eastern Africa, colorectal cancer was the fourth most frequently diagnosed cancer type. ${ }^{2}$ In Ethiopia, the second most populous country in sub-Saharan Africa, colorectal cancer is the most common cancer diagnosis in males and it ranks fourth in females. ${ }^{3}$ It is also responsible for $11.2 \%$ of cancer-related deaths in males and $4.8 \%$ of cancer-related deaths in females in Ethiopia. 
Gastrointestinal cancer patients have been reported to suffer from problems that emerged as a consequence of both the disease and the treatments, which negatively affect their quality of life. ${ }^{4}$ For instance, colorectal cancer symptoms and its treatments have several adverse effects and toxicity, which affect quality of life. ${ }^{5,6}$ Colorectal cancer patients have significantly lower physical, role, cognitive and social function compared to the general public. Moreover, they have a higher frequency of constipation, diarrhoea and financial difficulties. ${ }^{7-9}$ Thus, further research on health-related quality of life is recommended to guide decision making in treatment choice. ${ }^{10}$

The World Health Organization (WHO) defines "quality of life" as a broad concept that depends on a person's physical health, psychological state, level of freedom, social relationships, and personal beliefs. ${ }^{11}$ Cancer treatments have started incorporating quality of life as an end point. ${ }^{12}$ Thus, different sensitive, reliable and validated tools are available to assess quality of life among cancer patients. Frequently used tools are the core EORTC-QLQ, the Functional Assessment of Chronic Illness Therapy (FACIT) Measurement System, the Rotterdam Symptom Checklist (RSCL), and the Symptom Distress Scale (SDS). ${ }^{13}$ Of these, the core EORTC-QLQ has been recommended to be used when the aim of the study is to assess disease-specific symptoms. ${ }^{14,15}$ To complement the core EORTC-QLQ, different disease-specific modules have been developed, and the EORTC-QLQ for colorectal cancer patients (EORTC-QLQ-CR29) is one of these tools. This tool has been developed to be used alongside the core tool in colorectal cancer patients. This disease-specific tool has been validated in different countries such as Spain, Taiwan, Korea and China. ${ }^{16-19}$ Even though the Ethiopian Federal Ministry of Health has developed a strategy to assess and treat distressing symptoms in cancer patients, ${ }^{20}$ there are no validated tools to assess quality of life among colorectal cancer patients. Therefore, this study intended to examine the reliability and construct validity of EORTC-QLQ-CR29 tool among Ethiopian colorectal cancer patients.

\section{Materials and Methods}

\section{Study Design, Area and Participants}

A cross-sectional study was carried out at Tikur Anbessa Specialized Hospital (TASH) from March to May, 2020 in colorectal cancer patients. TASH is the largest referral and teaching hospital in Ethiopia, serving as the only radiotherapy centre in the country. In this oncology centre, there are two radiotherapy machines, 36 inpatient beds and 12 outpatient chemotherapy beds. There are also six clinical oncologists, who provide the oncology services. ${ }^{21}$

The sample size was calculated based on the recommendations of 5 to 10 participants /item for checking factor structure and validity of items given for scaling analysis. $^{22,23}$ The tool has 29 items; thus, a minimum sample size of 145 participant is required. However, within the study period, 160 participants were approached and 158 of them participated in the study. Since Amharic is the official working language of Ethiopia and is spoken by millions of Ethiopians as a second language, 158 pathologically-confirmed Amharic speaking colorectal cancer patients aged 18 years or older were included while being treated at the TASH oncology department.

\section{Instrument}

EORTC-QLQ-CR29 is a 29 -item module developed to complement the core EORTC-QLQ. It comprises 19 single items and four scales to assess urinary frequency, blood or mucus in the stool, stool frequency, body image, and other problems faced by patients. The tool scales are generally classified as functional and symptom scales. ${ }^{24}$ Since most patients do not have formal education, it may be difficult to use a self-administered questionnaire. Therefore, patients' socio-demographic, clinical characteristics, and quality of life data were collected using an interviewadministered questionnaire.

The EORTC-QLQ-CR29 tool was translated into Amharic according to the EORTC translation guidelines. ${ }^{25}$ Two native Amharic speakers independently translated the instrument from English to Amharic. These versions were discussed in the research group and a consensus was reached. After that, two proficient English speakers translated the Amharic version back to English. Then, it was sent to the EORTC translation group for reviewing and proofreading. After receiving the comments from the EORTC translation group, a pilot was conducted. The study was conducted to identify difficult, confusing and upsetting questions. None of the questions were found to be difficult, confusing or upsetting for the participants. Based on the recommendations from the pilot study, ${ }^{25}$ ten colorectal cancer patients took part in the pilot, and these participants were excluded from the actual study.

After the completion of the pilot study, the data collection commenced. The data was collected by two nurses who have bachelor's degrees and work in the oncology centre. 
Training on how to collect the data was given to the data collectors by the principal investigator for three days, focusing on the purpose of the study, contents of the questionnaire, and how to approach and get consent from patients. The principal investigator supervised the data collection process every other day to monitor the data collection procedure. Patients were approached in the waiting room while waiting for their turns. To ensure confidentiality and anonymity of the participants, code was used in the questionnaire instead of respondents' names.

\section{Data Analysis}

Descriptive statistics were used to assess the frequency distributions of socio-demographic characteristics and clinical data. Numbers and percentages were used for categorical variables and median, and interquartile range were used for continuous variables. The reliability was assessed using Cronbach's alpha. A value of Cronbach's alpha of 0.70 or greater was considered to be adequate. ${ }^{23}$

Convergent validity, the extent to which two measures are related to the same construct, was determined by employing Multitrait scaling analysis. Multitrait scaling analysis focuses on items as the unit of analysis. ${ }^{23}$

Known-groups validity was checked using the MannWhitney test to see whether the tool is able to detect differences between groups. The known groups that were used for comparison were treatment intent, physical function, and presence of stoma. ${ }^{24}$ Based on the median value of the physical scale of the core EORTC-QLQ, patients were classified as having better or worse physical function. Those patients with a median score of $\geq 43.3$ for the physical scale were considered to have better physical function whereas those below 43.3 were considered to have worse physical function. ${ }^{26}$

The correlations between the items of the colorectal cancer and core tools scales were determined using Pearson Correlation Coefficient. All scales and items were transformed into a $0-100$ score as per the EORTCQLQ scoring manual. ${ }^{27}$ Statistical analyses were performed using SPSS, version 21.

\section{Results}

\section{Socio-Demographic Characteristics of Respondents}

A total of 158 participants were included in this study, with a median age of $46(\mathrm{IQR}=17.7)$. About 50 (32.3\%) study participants had no formal education and were employed $(32.3 \%)$ while $45(28.5 \%)$ respondents had attended college. As presented in Table 1, the majority of the study participants were men (52.5\%), married (63.3\%), and residents of Addis (64.4\%).

\section{Clinical Characteristics of Respondents}

85 of the respondents $(53.8 \%)$ were treated for rectal cancer. Seventy-eight respondents (49.4\%) were being treated with chemotherapy alone. About 120 respondents (75.9\%) were treated with palliative intent. The majority of respondents $(72.2 \%)$ were stage-four cancer patients (Table 2).

\section{Reliability of EORTC-QLQ-CR29}

The reliability of the tool was examined based on the value of Cronbach's alpha coefficients (alpha $\geq 0.70$ ). As presented in Table 3, all of the scales had an alpha value of greater than or equal to 0.7, except for the Mucus and Blood in Stool scale (0.47). Urinary Frequency had the highest alpha value (0.91), followed by Stool Frequency (0.85).

\section{Construct Validity}

Convergent and Divergent Validity Results of Multitrait Scaling Analysis for EORTC-QLQ-CR29

Convergent and divergent validity were assessed in terms of item-own scale and item-other scale correlation, respectively. The item-own scale correlation was over 0.4 for all scales. Similarly, the item-own correlation for all scales was higher than the item-other scale correlation. As seen in Table 4, except for the Blood and Mucus in Stool scale, all scales have an item-own correlation of above 0.4 and an item-other scale correlation below the item-own scale correlation of 0.4 .

\section{The Correlation Between the Core EORTC-QLQ and CR29 Scales}

The correlation between the core EORTC-QLQ and CR29 scales ranged from -0.45 to 0.58 . The highest correlation was seen between the Body Image scale from the colorectal tool and the Emotional scale from the core questionnaire. The highest negative correlation was observed between Flatulence and Cognitive Function $(r=-0.45)$. Most of the correlations between the core EORTC-QLQ and CR29 were below 0.4 (Table 5).

\section{Known-Groups Validity of EORTC-QLQ- CR29}

To assess the known-groups validity of the tool, comparisons of scores of multi-item scales and single items of 
Table I Socio-Demographic Characteristics of Respondents at Tikur Anbessa Specialized Hospital, Addis Ababa, 2020

\begin{tabular}{|c|c|c|c|}
\hline Variable & Category & $\begin{array}{l}\text { Frequency } \\
(n=158)\end{array}$ & Percent (\%) \\
\hline \multirow[t]{2}{*}{ Sex } & Men & 83 & 52.5 \\
\hline & Women & 75 & 47.5 \\
\hline \multirow[t]{4}{*}{$\begin{array}{l}\text { Educational } \\
\text { status }\end{array}$} & $\begin{array}{l}\text { No formal } \\
\text { education }\end{array}$ & 51 & 32.3 \\
\hline & $\begin{array}{l}\text { Primary } \\
\text { education }\end{array}$ & 35 & 22.2 \\
\hline & $\begin{array}{l}\text { Secondary } \\
\text { education }\end{array}$ & 27 & 17.1 \\
\hline & $\begin{array}{l}\text { College and } \\
\text { above }\end{array}$ & 45 & 28.5 \\
\hline \multirow[t]{6}{*}{ Occupation } & Farmer & II & 7 \\
\hline & Employed & 51 & 32.3 \\
\hline & Housewife & 51 & 32.3 \\
\hline & Retired & II & 7 \\
\hline & Student & 19 & 12 \\
\hline & Merchant & 15 & 9.5 \\
\hline \multirow[t]{4}{*}{ Region } & Addis Ababa & 102 & 64.6 \\
\hline & Oromia & 27 & I7.I \\
\hline & Amhara & 17 & 10.8 \\
\hline & Others* & 12 & 7.5 \\
\hline \multirow[t]{4}{*}{ Marital status } & Married & 100 & 63.3 \\
\hline & Single & 28 & 17.7 \\
\hline & Divorced & 13 & 8.2 \\
\hline & Widowed & 17 & 10.8 \\
\hline \multirow[t]{3}{*}{ Age } & $18-45$ & 132 & 41.8 \\
\hline & $46-65$ & 170 & 53.8 \\
\hline & $>65$ & 14 & 4.4 \\
\hline
\end{tabular}

Notes: *Others = Tigray; Southern Nations, Nationalities and Peoples'; and Dire Dawa.

EORTC-QLQ-CR29 among three clinically-distinct groups were made. These three groups were treatment intent, presence of stoma and physical function. This study hypothesised that patients with a stoma had a higher symptom score for Embarrassment and a lower functional score for the Anxiety and Body Image items and scale. Similarly, patients with worse physical health
Table 2 Clinical Characteristics of Respondents in Tikur Anbessa Specialized Hospital, Addis Ababa, 2020

\begin{tabular}{|c|c|c|c|}
\hline Variables & Category & $\begin{array}{l}\text { Frequency } \\
(n=158)\end{array}$ & Percent (\%) \\
\hline \multirow{2}{*}{$\begin{array}{l}\text { Cancer } \\
\text { site }\end{array}$} & Colon & 73 & 46.2 \\
\hline & Rectum & 85 & 53.8 \\
\hline \multirow{6}{*}{$\begin{array}{l}\text { Type of } \\
\text { treatment }\end{array}$} & Chemotherapy only & 78 & 49.4 \\
\hline & $\begin{array}{l}\text { Surgery and } \\
\text { radiotherapy only }\end{array}$ & 16 & 10.1 \\
\hline & $\begin{array}{l}\text { Chemotherapy and } \\
\text { surgery only }\end{array}$ & 34 & 21.5 \\
\hline & $\begin{array}{l}\text { Chemotherapy and } \\
\text { radiotherapy only }\end{array}$ & 17 & 10.8 \\
\hline & CSR & 12 & 7.6 \\
\hline & Radiotherapy only & I & 0.6 \\
\hline \multirow{2}{*}{$\begin{array}{l}\text { Treatment } \\
\text { intent }\end{array}$} & Curative & 38 & 24.1 \\
\hline & Palliative & 120 & 75.9 \\
\hline \multirow{4}{*}{$\begin{array}{l}\text { Cancer } \\
\text { stage }\end{array}$} & Stage I & 7 & 4.4 \\
\hline & Stage II & 24 & 15.2 \\
\hline & Stage III & 13 & 8.2 \\
\hline & Stage IV & 114 & 72.2 \\
\hline
\end{tabular}

Abbreviation: CSR, chemotherapy, surgery and radiotherapy.

Table 3 Cronbach's Alpha Values of EORTC-QLQ-CR29 Scales in Tikur Anbessa Specialized Hospital, Addis Ababa, 2020

\begin{tabular}{|l|l|l|}
\hline Scale Name & $\begin{array}{l}\text { Number of } \\
\text { Items }\end{array}$ & $\begin{array}{l}\text { Cronbach's Alpha } \\
\text { Coefficients }\end{array}$ \\
\hline Urinary Frequency & 2 & 0.91 \\
\hline Mucus and Blood in Stool & 2 & 0.47 \\
\hline Body Image & 3 & 0.70 \\
\hline Stool Frequency & 2 & 0.85 \\
\hline
\end{tabular}

and palliative patients were expected to have higher scores for the symptom items and scales and lower scores for functional scales and items.

The Mann-Whitney test revealed that there was no significant difference between the curative and the palliative treatment groups in any of the scores of the colorectal tool scales or items. In patients with and without a stoma, the presence of a stoma led to a deterioration in quality of life by increasing Urinary Frequency, Flatulence, Embarrassment and Anxiety. 
Table 4 Construct Validity for EORTC-QLQ-CR29 Scales in Tikur Anbessa Specialized Hospital, Addis Ababa, 2020

\begin{tabular}{|l|l|l|l|l|l|}
\hline Scale & $\begin{array}{l}\text { Item } \\
\text { Numbers }\end{array}$ & $\begin{array}{l}\text { Item-Own Scale } \\
\text { Correlation }\end{array}$ & $\begin{array}{l}\text { Item-Own Scale Correlation After } \\
\text { Correction Overlap }\end{array}$ & $\begin{array}{l}\text { Item-Other Scale } \\
\text { Correlation }\end{array}$ & \begin{tabular}{l} 
P-value \\
\hline Urinary Frequency
\end{tabular} \\
\hline 1,32 & $0.94-0.96$ & 0.81 & $-0.33-0.34$ & $<0.001$ \\
\hline Blood and Mucus in Stool & 38,39 & $0.74-0.79$ & 0.24 & $-0.31-0.35$ & $<0.001$ \\
\hline Stool Frequency & 52,53 & $0.92-0.93$ & 0.73 & $-0.33-0.35$ & $<0.001$ \\
\hline Body Image & $45-47$ & $0.75-0.81$ & $0.51-0.55$ & $-(0.4-0.19)$ & $<0.001$ \\
\hline
\end{tabular}

Table 5 The Correlation Between the Core EORTC QLQ and CR 29 Scales in Tikur Anbessa Specialized Hospital, Addis Ababa, 2020

\begin{tabular}{|c|c|c|c|c|c|c|c|c|c|}
\hline & PF & $\mathbf{R F}$ & PA & FA & NV & CF & EF & SF & QoL \\
\hline Urinary Frequency & -0.04 & -0.01 & -0.01 & 0.01 & 0.01 & 0.11 & $-0.23^{b}$ & $-0.02^{\mathrm{a}}$ & 0.12 \\
\hline Urinary Incontinence & $-0.24^{b}$ & $-0.24^{\mathrm{b}}$ & $0.17^{\mathrm{a}}$ & $0.17^{\mathrm{a}}$ & 0.14 & $-0.23^{b}$ & $-0.2 I^{b}$ & $-0.39^{b}$ & 0.09 \\
\hline Dysuria & $-0.275^{b}$ & $-0.34^{\mathrm{b}}$ & $0.30^{\mathrm{b}}$ & $0.24^{\mathrm{b}}$ & $0.43^{b}$ & $-0.210^{\mathrm{b}}$ & $-0.33^{b}$ & $-0.32^{\mathrm{b}}$ & -0.13 \\
\hline Abdominal Pain & -0.14 & -0.10 & $0.38^{\mathrm{b}}$ & $0.36^{\mathrm{b}}$ & $0.24^{\mathrm{b}}$ & -0.14 & -0.08 & -0.04 & 0.07 \\
\hline Buttock Pain & -0.13 & $-0.19^{a}$ & 0.09 & 0.02 & $0.24^{b}$ & 0.10 & -0.14 & $-0.19^{a}$ & $-0.19^{2}$ \\
\hline Bloating & $-0.27^{b}$ & $-0.23^{b}$ & $0.21^{\mathrm{b}}$ & $0.25^{\mathrm{b}}$ & $0.17^{\mathrm{a}}$ & $-0.19^{a}$ & $-0.3 I^{b}$ & -0.15 & 0.09 \\
\hline Blood and Mucus in Stool & $-0.17^{\mathrm{a}}$ & -0.10 & $0.24^{\mathrm{b}}$ & $0.35^{\mathrm{b}}$ & $0.18^{\mathrm{a}}$ & $-0.35^{b}$ & $-0.17^{\mathrm{a}}$ & -0.13 & $0.26^{\mathrm{b}}$ \\
\hline Dry Mouth & $-0.30^{\mathrm{b}}$ & -0.12 & $0.20^{\mathrm{a}}$ & $0.33^{\mathrm{b}}$ & 0.02 & $-0.25^{\mathrm{b}}$ & $-0.21^{b}$ & $-0.17^{\mathrm{a}}$ & $0.25^{\mathrm{b}}$ \\
\hline Hair Loss & $-0.35^{\mathrm{b}}$ & $-0.27^{\mathrm{b}}$ & $0.36^{\mathrm{b}}$ & $0.30^{\mathrm{b}}$ & $0.38^{\mathrm{b}}$ & $-0.36^{\mathrm{b}}$ & -0.09 & $-0.20^{\mathrm{a}}$ & 0.04 \\
\hline Taste & $-0.3 I^{b}$ & $-0.32^{b}$ & $0.40^{\mathrm{b}}$ & $0.44^{b}$ & $0.32^{\mathrm{b}}$ & $-0.3 I^{b}$ & -0.06 & $-0.19^{a}$ & -0.03 \\
\hline Anxiety & $0.29^{\mathrm{b}}$ & $0.26^{\mathrm{b}}$ & -0.02 & -0.05 & -0.01 & -0.07 & $0.33^{\mathrm{b}}$ & $0.23^{\mathrm{b}}$ & 0.10 \\
\hline Weight & $0.31^{b}$ & $0.24^{b}$ & -0.11 & -0.15 & $-0.21^{b}$ & $0.21^{\mathrm{b}}$ & $0.32^{\mathrm{b}}$ & $0.333^{b}$ & -0.05 \\
\hline Body Image & $0.45^{\mathrm{b}}$ & $0.26^{\mathrm{b}}$ & $-0.30^{\mathrm{b}}$ & $-0.29^{b}$ & $-0.22^{b}$ & $0.25^{\mathrm{b}}$ & $0.58^{\mathrm{b}}$ & $0.30^{\mathrm{b}}$ & 0.00 \\
\hline Flatulence & $-0.4 I^{\mathrm{b}}$ & $-0.3 I^{\mathrm{b}}$ & $0.37^{\mathrm{b}}$ & 0.11 & $0.35^{\mathrm{b}}$ & $-0.45^{\mathrm{b}}$ & -0.12 & $-0.28^{\mathrm{b}}$ & 0.15 \\
\hline Faecal Incontinence & $-0.32^{b}$ & $-0.43^{b}$ & $0.29^{\mathrm{b}}$ & $0.17^{\mathrm{a}}$ & $0.30^{\mathrm{b}}$ & $-0.39^{b}$ & $-0.34^{\mathrm{b}}$ & $-0.34^{b}$ & 0.04 \\
\hline Sore Skin & $-0.20^{\mathrm{a}}$ & $-0.37^{b}$ & $0.28^{\mathrm{b}}$ & 0.04 & $0.37^{b}$ & -0.11 & $-0.33^{b}$ & $-0.239^{b}$ & 0.08 \\
\hline Stool Frequency & $-0.23^{b}$ & $-0.3 I^{b}$ & $0.17^{\mathrm{a}}$ & 0.11 & $0.18^{\mathrm{a}}$ & 0.06 & $-0.38^{\mathrm{b}}$ & -0.14 & -0.07 \\
\hline Embarrassment & -0.12 & $-0.16^{\mathrm{a}}$ & 0.03 & 0.09 & 0.08 & 0.06 & $-0.31^{\mathrm{b}}$ & -0.11 & 0.10 \\
\hline Stoma Care Problem & -0.15 & -0.12 & 0.03 & -0.08 & -0.03 & 0.07 & $-0.26^{\mathrm{b}}$ & -0.14 & -0.07 \\
\hline Sexual Interest Men & -0.14 & -0.11 & 0.05 & 0.11 & 0.03 & 0.04 & 0.02 & $-0.16^{\mathrm{a}}$ & -0.12 \\
\hline Impotence & 0.03 & 0.15 & -0.09 & -0.08 & $-0.17^{\mathrm{a}}$ & -0.02 & -0.04 & 0.02 & 0.15 \\
\hline Sexual Interest Women & -0.09 & -0.08 & 0.06 & -0.09 & -0.14 & -0.04 & -0.06 & 0.00 & $0.17^{\mathrm{a}}$ \\
\hline Dyspareunia & 0.08 & 0.11 & -0.07 & 0.07 & 0.11 & 0.01 & 0.05 & -0.06 & -0.12 \\
\hline
\end{tabular}

Notes: ${ }^{\mathrm{b} C}$ Correlation is significant at the 0.05 level, ${ }^{\mathrm{a}}$ Correlation is significant at the 0.01 level.

Abbreviations: PF, physical function; RF, role function; PA, pain; FA, fatigue; NV, nausea and vomiting; CF, cognitive function; EF, emotional function; SF, social function; QoL, quality of life. 
Patients with better physical function scored higher for functional items and scales and scored lower for symptom items and scales. This suggested the known-groups validity of the tool is fulfilled. (Details are presented in Table 6.)

\section{Discussion}

The purpose of this study was to examine the reliability and construct validity of the Amharic version of the EORTC-
QLQ-CR29 among Ethiopian colorectal cancer patients. In our study, the tool was found to be reliable. Its internal consistency values ranged from 0.47 to 0.91 . All scales had Cronbach's alpha values of above 0.7, except for the Blood and Mucus in Stool scale. This finding concurs with the Dutch and original studies. ${ }^{24-28}$ However, this finding differed from Korean and Taiwanese studies, ${ }^{17,18}$ which found Cronbach-alpha values of greater than 0.7 for all scales.

Table 6 Known-Groups Comparison: Scales and Items in the EORTC-QLQ-CR29 for Clinically-Distinct Groups in Tikur Anbessa Specialized Hospital, Addis Ababa, 2020

\begin{tabular}{|c|c|c|c|c|c|c|c|c|c|}
\hline \multirow[t]{3}{*}{ CR-29 } & \multicolumn{3}{|c|}{ Treatment Mean Rank Value } & \multicolumn{3}{|c|}{ Presence of Stoma } & \multicolumn{3}{|c|}{ Physical Function } \\
\hline & \multirow{2}{*}{$\begin{array}{l}\text { Curative } \\
n=38\end{array}$} & \multirow{2}{*}{$\begin{array}{l}\text { Palliative } \\
n=120\end{array}$} & \multirow[t]{2}{*}{$P$ value } & \multirow{2}{*}{$\begin{array}{l}\text { Yes } \\
n=60\end{array}$} & \multirow{2}{*}{$\begin{array}{l}\text { No } \\
\mathbf{N}=\mathbf{9 8}\end{array}$} & \multirow[t]{2}{*}{$P$ value } & \multirow{2}{*}{$\begin{array}{l}\text { Worse } \\
n=79\end{array}$} & \multirow{2}{*}{$\begin{array}{l}\text { Better } \\
n=79\end{array}$} & \multirow[t]{2}{*}{ p-value } \\
\hline & & & & & & & & & \\
\hline $\mathrm{BI}$ & 76.03 & 80.60 & 0.84 & 79.01 & 79.80 & 0.92 & 66.99 & 92.01 & $<0.001$ \\
\hline AN & 78.25 & 79.90 & 1.00 & 65.95 & 87.80 & 0.002 & 74.37 & 84.63 & 0.13 \\
\hline WET & 76.22 & 80.54 & 0.99 & 80.73 & 78.74 & 0.78 & 73.11 & 85.89 & 0.07 \\
\hline SXM & 34.65 & 44.33 & 0.10 & 47.27 & 38.70 & 0.87 & 16.67 & 45.67 & 0.25 \\
\hline sXW & 36.28 & 38.54 & 0.64 & 39.18 & 37.30 & 0.49 & 43.13 & 31.81 & 0.07 \\
\hline UFR & 79.53 & 79.49 & 1.00 & 89.78 & 73.21 & 0.02 & 80.06 & 78.94 & 0.87 \\
\hline BM & 82.18 & 78.65 & 0.99 & 69.50 & 85.6 & 0.02 & 84.40 & 74.60 & 0.15 \\
\hline STF & 78.59 & 79.79 & 0.98 & 86.78 & 75.04 & 0.11 & 83.23 & 75.77 & 0.30 \\
\hline URI & 82.92 & 78.42 & 0.97 & 82.53 & 33.33 & 0.49 & 82.09 & 76.91 & 0.45 \\
\hline DY S & 87.25 & 77.05 & 0.80 & 77.85 & 80.51 & 0.70 & 89.18 & 69.82 & 0.00 \\
\hline $\mathrm{ABP}$ & 79.08 & 79.63 & 1.00 & 69.20 & 85.81 & 0.02 & 88.94 & 70.06 & 0.01 \\
\hline BTP & 74.57 & 81.06 & 0.86 & 84.89 & 76.20 & 0.23 & 82.50 & 76.50 & 0.39 \\
\hline BLO & 76.63 & 80.41 & 1.00 & 75.12 & 82.18 & 0.30 & 88.21 & 70.79 & 0.01 \\
\hline DRM & 75.83 & 80.66 & 0.87 & 80.37 & 78.97 & 0.84 & 91.20 & 67.80 & $<0.001$ \\
\hline HRL & 87.16 & 77.08 & 0.60 & 66.35 & 87.55 & $<0.001$ & 93.04 & 65.96 & $<0.001$ \\
\hline TAT & 75.39 & 80.80 & 0.99 & 68.37 & 86.32 & 0.01 & 90.32 & 68.68 & $<0.001$ \\
\hline FLU & 76.59 & 80.42 & 0.99 & 89.68 & 73.27 & 0.02 & 95.54 & 63.46 & $<0.001$ \\
\hline FEI & 74.55 & 81.07 & 1.00 & 88.01 & 74.29 & 0.05 & 87.53 & 71.47 & 0.02 \\
\hline SOS & 77.55 & 80.12 & 0.96 & 80.12 & 79.12 & 0.89 & 84.40 & 74.60 & 0.16 \\
\hline EMB & 83.78 & 78.15 & 0.96 & 108.25 & 61.90 & $<0.001$ & 82.70 & 76.30 & 0.34 \\
\hline SCR & 34.19 & 29.48 & 0.47 & NA & NA & NA & 35.05 & 25.95 & 0.03 \\
\hline IMP & 35.58 & 44.04 & 0.16 & 48.77 & 37.75 & 0.16 & 45.12 & 39.37 & 0.12 \\
\hline DYS & 43.47 & 36.27 & 0.64 & 34.91 & 39.84 & 0.37 & 35.57 & 40.93 & 0.23 \\
\hline
\end{tabular}

Abbreviations: BI, body image; AN, anxiety; WET, weight; SXM, sexual interest (men); SXF, sexual interest (women); UFR, urinary frequency; BM, blood and mucus in stool; STF, stool frequency; URI, urinary incontinence; DYS, dysuria; ABP, abdominal pain; BTP, buttock pain; BLO, bloating; DRM, dry mouth; HRL, hair loss; TAT, taste; FLU, flatulence; FEl, faecal incontinence; SOS, sore skin; EMB, embarrassment; SCR, stoma care problem; IMP, impotence; DYP, dyspareunia; NA, not applicable. 
All-items correlations within their scales were greater than 0.4, except for the Blood and Mucus in Stool scale. This is similar to the results seen in a Spanish study. ${ }^{16}$ However, this is inconsistent with the previous findings where it was shown that the Blood and Mucus in Stool scale had convergent and divergent validity. ${ }^{17-19,24,28}$ The different findings reveal that limited variability in item score has an effect on correlation. ${ }^{29}$ Thus, lower variability in our study might explain the difference. In fact, the items that comprise the Blood and Mucus in Stool scale may not correlate with each other.

Known-group comparison was performed to check whether the tool was able to detect differences between distinct groups. Our findings are consistent with studies conducted in Spain, China and the Netherlands, ${ }^{16,19,24,28}$ where the tool was found to differentiate between the groups. However, the Body Image and Sore Skin items did not discriminate between patients with and without stoma. This is inconsistent with previous findings where a difference was seen according to the presence of a stoma. ${ }^{16,19,24,28}$ This difference might be due to the fact that, in our study, there was an age difference between stoma and non-stoma patients. However, the previous studies did not report the age of stoma and non-stoma patients. In the current study, patients in the stoma groups were older than those in the non-stoma groups. Based on a study conducted in Australia, elderly patients have a greater appreciation for their function and body image. $^{30}$ Similarly, the scales and items did not differentiate curative and palliative patients. This could be explained by the fact that, in our study, the sample size is smaller in the curative group.

The correlation between the core EORTC-QLQ and CR29 ranged from "weak" to "moderate". The highest correlation was observed between the Emotional and Body Image scales. This agrees with studies conducted in Korea and Spain. ${ }^{16,18}$ This result suggests that the tools are designed to cover different dimensions of healthrelated quality of life. Therefore, the core questionnaire should be used along the specific module.

In general, the original tool was made in English. English is not widely spoken in Ethiopia. Therefore, the tool may not be understood in the same way in Ethiopia. There are also cultural differences between Ethiopia and where the original tool was first developed. On top of all these, there is also a lack of studies on the validity of the tool in Africa. Thus, this study can fill the gaps observed in Africa.

\section{Strengths and Limitation of the Study}

While the translation of the tool was done, every step of the EORTC translation process was followed, under the supervision of the EORTC translation group. Nonetheless, this study had its own limitations. Even though patients were included irrespective of their place of residence, treatment and disease stage, most of them were in the final stages of cancer. This is because most cancer patients in Ethiopia come to hospital at the late stages of the disease.

\section{Conclusion}

The current study supported the reliability and validity of the Amharic version of the EORTC-QLQ-CR29 among Ethiopian colorectal cancer patients. We also recommend that researchers and clinicians use the core questionnaire alongside the disease-specific module while assessing health-related quality of life in colorectal cancer patients. Specific support for each patient should be focused on the individual domains and items which eventually contribute to lower quality of life.

\section{Abbreviations}

EORTC-QLQ, European Organization for Research and Treatment of Cancer Quality of Life questionnaire; EORTC-QLQ-CR29, European Organization for Research and Treatment of Cancer Quality of Life questionnaire for colorectal cancer patients; FACIT, Functional Assessment of Chronic Illness Therapy; GLOBOCAN, Global Organization Board of Cancer Association Network; PCA, Principal Component Analysis; QoL, Quality of life; SDS, The Symptom Distress Scale; WHO, World Health Organization.

\section{Data Sharing Statement}

The data are available from the corresponding author on reasonable request.

\section{Ethics Approval and Consent to Participate}

Ethical clearance was obtained from the Ethical Clearance Committee of Addis Ababa University (AAU) College of Health Science, School of Public Health Ethical Review Committee. Permission to use the questionnaires was secured from the EORTC research group using an online form at https://qol.eortc.org/form. Informed written 
consent was given by all participants. This study was conducted in accordance with the Declaration of Helsinki.

\section{Acknowledgments}

The authors would like to thank Addis Ababa University for funding this study. We would like to express our sincere gratitude to all participants and those who supported the study. In loving memory of our friend and colleague, Dr. Aynalem Abraha Woldemariam.

\section{Funding}

This study was funded by Addis Ababa University for partial fulfilment of a Master's degree in Public Health with a specialty in Epidemiology and Biostatistics by the first author.

\section{Disclosure}

The authors declare that they have no conflicts of interest for this work.

\section{References}

1. Bray F, Ferlay J, Soerjomataram I, Siegel RL, Torre LA, Jemal A. Global cancer statistics 2018: GLOBOCAN estimates of incidence and mortality worldwide for 36 cancers in 185 countries. CA Cancer J Clin. 2018;68:394-424. doi:10.3322/caac.21492

2. Ferlay J, Ervik M, Lam F, et al. Global Cancer Observatory: Cancer Today. Lyon, France: International Agency for Research on Cancer; 2020.

3. Memirie ST, Habtemariam MK, Asefa M, et al. Estimates of cancer incidence in Ethiopia in 2015 using population-based registry data. J Glob Oncol. 2018;1-11. doi:10.1200/JGO.17.00175

4. Numico G, Longo V, Courthod G, Silvestris N. Cancer survivorship: long-term side-effects of anticancer treatments of gastrointestinal cancer. Curr Opin Oncol. 2015;27:351-357. doi:10.1097/ CCO.0000000000000203

5. Akhlaghi E, Lehto RH, Torabikhah M, et al. Chemotherapy use and quality of life in cancer patients at the end of life: an integrative review. Health Qual Life Outcomes. 2020;18(1):1-9. doi:10.1186/ s12955-020-01580-0

6. Birgisson H, Påhlman L, Gunnarsson U, Glimelius B. Late adverse effects of radiation therapy for rectal cancer - a systematic overview. Acta Oncol. 2007;46(4):504-516. doi:10.1080/02841860701348670

7. Grosek J, Novak J, Kitek K, Bajric A, Majdic A, Kosir JA. Healthrelated quality of life in Slovenian patients with colorectal cancer: a single tertiary care center study. Radiol Oncol. 2019;53 (2):231-237. doi:10.2478/raon-2019-0015

8. Arndt V, Merx H, Stegmaier C, Ziegler H, Brenner H. Quality of life in patients with colorectal cancer 1 year after diagnosis compared with the general population: a population-based study. J Clin Oncol. 2004;22(23):4829-4836. doi:10.1200/JCO.2004.02.018

9. Jansen L, Koch L, Brenner H, Arndt V. Quality of life among longterm (P 5 years) colorectal cancer survivors - systematic review. Eur J Cancer. 2010;46(16):2879-2888. doi:10.1016/j.ejca.2010.06.010

10. Blazeby JM, Avery K, Sprangers M, Pikhart H, Fayers P, Donovan J. Health-related quality of life measurement in randomized clinical trials in surgical oncology. J Clin Oncol. 2015;24(19):3178-3184. doi:10.1200/JCO.2005.05.2951
11. World Health Organization. Division of Mental Health and Prevention of Substance Abuse. WHOQOL: Measuring Quality of Life. World Health Organization; 1997.

12. Bonnetain F, Borg C, Adams RR, et al. How health-related quality of life assessment should be used in advanced colorectal cancer clinical trials. Ann Oncol. 2017;28(9):2077-2085. doi:10.1093/annonc/mdx191

13. Tamburini M. Health-related quality of life measures in cancer. Ann Oncol. 2001;12:8-10. doi:10.1093/annonc/12.suppl_3.S7

14. Pallis AG, Mouzas IA. Instruments for quality of life assessment in patients with gastrointestinal cancer. Anticancer Res. 2004;24 (3b):2117-2121.

15. Luckett T, King MT, Butow PN, Heading G. Choosing between the EORTC QLQ-C30 and FACT-G for measuring health-related quality of life in cancer clinical. Ann Oncol. 2011;22(10):2179-2190. doi:10.1093/annonc/mdq721

16. Arraras JI, Suárez J, Arias de la Vega F, et al. The EORTC Quality of Life questionnaire for patients with colorectal cancer: EORTC QLQ-CR29 validation study for Spanish patients. Clin Transl Oncol. 2011;13(1):50-56. doi:10.1007/s12094-011-0616-y

17. Shen M, Chen L, Ho T, Shih Y, Huang C, Chie W. Validation of the Taiwan Chinese version of the EORTC QLQ-CR29 to assess quality of life in colorectal cancer patients. BMC Cancer. 2018;18:1-10. doi:10.1186/s12885-017-3892-2

18. Ihn MH, Lee S, Son IT, et al. Cultural adaptation and validation of the Korean version of the EORTC QLQ-CR29 in patients with colorectal cancer. Support Care Cancer. 2015;23:3493-3501. doi:10.1007/ s00520-015-2710-0

19. Lin J, Zhang L, Wu D, et al. Validation of the Chinese version of the EORTC QLQ-CR29 in patients with colorectal cancer. World J Gastroenterol. 2017;23(10):1891-1898. doi:10.3748/wjg.v23.i10.1891

20. Kifle M, Abdella K, Moge T, Tsegaye T, Moges A. National cancer control plan of Ethiopia. 2015.

21. Deressa BT, Cihoric N, Tefesse E, Assefa M, Zemenfes D. Multidisciplinary cancer management of colorectal cancer in Tikur Anbessa Specialized Hospital, Ethiopia. J Glob Oncol. 2019;5:1-7. doi:10.1200/JGO.19.00014

22. Norman GR, Streiner DL. Biostatistics - the bare essentials. In: Mehta L, McKeon M, editors. An Introductory Course in Statistics (Preferably, Applied Statistics). 4th ed. USA: People's Medical Publishing House; 2014:937.

23. Kyriazos TA. Applied psychometrics: sample size and sample power considerations in factor analysis (EFA, CFA) and SEM in general. Psychology. 2018;9(08):2207-2230. doi:10.4236/psych.2018.98126

24. Whistance RN, Conroy T, Chie W, et al. Clinical and psychometric validation of the EORTC QLQ-CR29 questionnaire module to assess health-related quality of life in patients with colorectal cancer. Eur J Cancer. 2009;45(17):3017-3026. doi:10.1016/j.ejca.2009.08.014

25. Dewolf L, Koller M, Velikova G, et al. EORTC Quality of Life Group Translation Procedure. 3rd ed. Brussels, Belgium: EORTC Quality of Life Group; 2009:32.

26. Koller M, Lorenz W. Quality of life: a deconstruction for clinicians. J R Soc Med. 2002;95(10):481-488. doi:10.1177/014107680209501002

27. Fayers PM, Aaronson NK, Bjordal K, Groenvold M, Curran D, Bottomley A; on behalf of the EORTC Quality of Life Group. The EORTC QLQ-C30 Scoring Manual. 3rd ed. EORTC Quality of Life Group: Brussels, Belgium; 2001.

28. Stiggelbout AM, Kunneman M, Baas-thijssen MCM, Neijenhuis PA. The EORTC QLQ-CR29 quality of life questionnaire for colorectal cancer: validation of the Dutch version. Qual Life Res. 2016;25:1853-1858. doi:10.1007/s11136-015-1210-5

29. Goodwin LD, Leech NL. Understanding correlation: factors that affect the size of r. $J$ Exp Educ. 2006;74(3):249-266. doi:10.3200/ JEXE.74.3.249-266

30. Tiggemann M, McCourt A. Body appreciation in adult women: relationships with age and body satisfaction. Body Image. 2013;10 (4):624-627. doi:10.1016/j.bodyim.2013.07.003 


\section{Publish your work in this journal}

Cancer Management and Research is an international, peer-reviewed open access journal focusing on cancer research and the optimal use of preventative and integrated treatment interventions to achieve improved outcomes, enhanced survival and quality of life for the cancer patient.
The manuscript management system is completely online and includes a very quick and fair peer-review system, which is all easy to use. Visit http://www.dovepress.com/testimonials.php to read real quotes from published authors. 